\title{
Role of tumor size in the pre-operative management of rectal cancer patients
}

\author{
Inti Zlobec ${ }^{*+1}$, Parham Minoo ${ }^{+2}$, Eva Karamitopoulou³ ${ }^{3}$ George Peros ${ }^{4}$, Efstratios S Patsouris 5 , Frank Lehmann ${ }^{6}$ and \\ Alessandro Lugli?
}

\begin{abstract}
Background: Clinical management of rectal cancer patients relies on pre-operative staging. Studies however continue to report moderate degrees of over/understaging as well as inter-observer variability. The aim of this study was to determine the sensitivity, specificity and accuracy of tumor size for predicting $\mathrm{T}$ and $\mathrm{N}$ stages in pre-operatively untreated rectal cancers.

Methods: We examined a test cohort of 418 well-documented patients with pre-operatively untreated rectal cancer admitted to the University Hospital of Basel between 1987 and 1996. Classification and regression tree (CART) and logistic regression analysis were carried out to determine the ability of tumor size to discriminate between early (pT1-2) and late (pT3-4) T stages and between node-negative ( $\mathrm{pNO}$ ) and node-positive (pN1-2) patients. Results were validated by an external patient cohort $(n=28)$.

Results: A tumor diameter threshold of $34 \mathrm{~mm}$ was identified from the test cohort resulting in a sensitivity and specificity for late T stage of $76.3 \%$, and $67.4 \%$, respectively and an odds ratio (OR) of 6.67 (95\%Cl:3.4-12.9). At a threshold value of $29 \mathrm{~mm}$, sensitivity and specificity for node-positive disease were $94 \%$ and $15.5 \%$, respectively with an OR of 3.02 (95\%Cl:1.5-6.1). Applying these threshold values to the validation cohort, sensitivity and specificity for $\mathrm{T}$ stage were $73.7 \%$ and $77.8 \%$ and for $\mathrm{N}$ stage $50 \%$ and $75 \%$, respectively.

Conclusions: Tumor size at a threshold value of $34 \mathrm{~mm}$ is a reproducible predictive factor for late T stage in rectal cancers. Tumor size may help to complement clinical staging and further optimize the pre-operative management of patients with rectal cancer.
\end{abstract}

\section{Background}

Clinical management of patients with rectal cancer depends significantly on pre-operative staging. Parameters such as $\mathrm{cT}$ and $\mathrm{cN}$ stage obtained by magnetic resonance imaging (MRI), computed tomography (CT) or endorectal ultrasonography (EUS) are crucial in selecting patients for pre-operative neoadjuvant therapy [1,2]. According to the European Society of Medical Oncology (ESMO), patients with T1-2, some early T3 and lymph node-negative disease may benefit most from surgery alone, whereas patients with more locally advanced stages (most T3, some T4 and those with lymph node positivity) are recommended for pre-operative radiother-

\footnotetext{
* Correspondence: izlobec@uhbs.ch

1 Institute of Pathology, University Hospital of Basel, Basel, Switzerland + Contributed equally

Full list of author information is available at the end of the article
}

apy followed by total mesorectal excision (TME) with the goal of decreasing local recurrence rates $[3,4]$.

However, recent studies report variability in the accuracy of pre-operative staging of rectal cancer. All three methods (CT, MRI and EUS) can lead to moderate rates of over- or understaging of $\mathrm{T}$ and $\mathrm{N}$ stages compared to histology in pre-operatively untreated patients [5-10]. Whereas EUS or CT seem to be more accurate for the detection of early $\mathrm{T} 1 / \mathrm{T} 2$ cancer, understaging with $\mathrm{CT}$ has been described for T3 tumors in comparison to MRI [10-13]. In contrary, lymph node positivity may be best detected by MRI, although inter-observer variability using this method has been described [14-19]. Overall, clinical imaging appears to result in an overall accuracy of $65 \%-90 \%$ and is closely related to observer experience [1]. Taken together, detection of novel prognostic factors capable of complementing clinical staging is warranted to 
identify patients in the pre-operative setting with locally advanced disease.

We and other groups have suggested that protein biomarkers in the pre-operative biopsy may help to identify patients with poor survival who might be candidates for neoadjuvant therapy [20]. Such biomarkers include the epidermal growth factor receptor (EGFR) and vascular endothelial growth factor (VEGF), among others [21-23]. To date, despite promising results, no single immunohistochemical protein marker has been introduced into daily practice. This may in large part be due to the lack of standardized scoring systems for evaluating immunohistochemistry results.

The tumor diameter plays an integral part in cancer staging in certain tumor types, such as stage I to III breast cancer and gastric cancer [24]. In the latter group, tumor size has been reported to be an independent prognostic factor of both $\mathrm{pT}$ and $\mathrm{pN}$ stages [25-29]. In fact, the strong link between tumor size, $\mathrm{pT}$ and $\mathrm{pN}$ stages has also been used to provide evidence supporting the cause of death of Emperor Napoleon Bonaparte from gastric cancer [30].

Only limited data have been published regarding the role of tumor size in predicting $\mathrm{T}$ and $\mathrm{N}$ stages in untreated rectal cancer patients. If an association could be demonstrated, it would provide crucial information for clinical staging. The aim of this study was to determine the sensitivity, specificity and accuracy of tumor size for predicting $\mathrm{T}$ and $\mathrm{N}$ stages in rectal cancers. To this end, we evaluated 418 patients with rectal cancers who received no pre-operative therapy, therefore tumor size and its predictive value was elaborated based on $\mathrm{pT}$ and $\mathrm{pN}$ stages confirmed pathologically. Results were subsequently validated by an external patient cohort.

\section{Methods}

\section{Test Cohort}

482 untreated, unselected rectal cancer patients admitted to the University Hospital of Basel between 1987 and 1996 were initially included in this study. Haematoxylin and eosin (H\&E) stained slides were retrospectively collected from the Institute of Pathology, University Hospital of Basel, the Institute of Clinical Pathology, Basel, Switzerland and the Institute of Pathology, Stadtspital Triemli, Zürich, Switzerland. Histopathological criteria were reviewed by an experienced gastrointestinal pathologist and included tumor diameter, $\mathrm{pT}$ and $\mathrm{pN}$ classification, grade of differentiation, histologic subtype, and the presence of tumor invasion into vessels. Clinical data including patient age at diagnosis, tumor location and follow-up were obtained from patient records. Cancer-specific survival time was the main clinical endpoint of interest. Censored observations included patients who were alive at the last follow-up, died for reasons other than colorectal cancer or were lost to follow-up. 5-year cancer-specific survival rate was 57\% (95\%CI: 51-61). Patient characteristics are summarized in Table 1 . The use of patient data has been approved by the local Ethics Committee of the University of Basel, Switzerland.

\section{External Validation Cohort}

28 non-consecutive rectal cancer patients treated at the 4th Department of Surgery, University of Athens Medical School were randomly selected from the archives of the 2nd Department of Pathology, University of Athens Medical School (Attikon University Hospital), Greece. Patients were treated between 2004 and 2006. All histo-

\section{Table 1: Characteristics of rectal cancer patients in the test} cohort $(n=418)$

\begin{tabular}{|c|c|c|}
\hline $\begin{array}{l}\text { Clinco-pathological } \\
\text { features }\end{array}$ & & Frequency N (\%) \\
\hline $\begin{array}{l}\text { Patient age at diagnosis } \\
\text { (years) }\end{array}$ & Median (min-max) & $69.0(36-96)$ \\
\hline Tumor size (mm) & Median (min-max) & $45.0(12-100)$ \\
\hline \multirow[t]{2}{*}{ Gender } & Male & $197(47.1)$ \\
\hline & Female & $221(52.9)$ \\
\hline \multirow[t]{2}{*}{ Diagnosis } & Non-mucinous & $18(4.3)$ \\
\hline & Mucinous & $400(95.7)$ \\
\hline \multirow[t]{2}{*}{ pT classification } & pT1-2 & $119(28.5)$ \\
\hline & pT3-4 & $299(71.5)$ \\
\hline \multirow[t]{2}{*}{ pN classification } & pNO & $226(54.1)$ \\
\hline & $\mathrm{pN} 1-2$ & $192(45.9)$ \\
\hline \multirow[t]{2}{*}{ Tumor grade } & G1-2 & $392(94.2)$ \\
\hline & G3 & $24(5.8)$ \\
\hline \multirow[t]{2}{*}{ Vascular invasion } & Absent & $311(74.8)$ \\
\hline & Present & $105(25.2)$ \\
\hline \multirow[t]{2}{*}{ Distant metastasis } & Absent & 77 (90.6) \\
\hline & Present & $8(9.4)$ \\
\hline \multirow[t]{2}{*}{ Post-operative therapy } & None & $66(77.7)$ \\
\hline & Treated & $19(22.4)$ \\
\hline Survival rate (5-years) & $95 \% \mathrm{Cl}$ & $56.9(52-62)$ \\
\hline
\end{tabular}


morphological data were reviewed from the corresponding hematoxylin and eosin (H\&E) stained slides, while clinical data were obtained from corresponding reports. Information included gender, age, tumor diameter, histological subtype, tumor location, $\mathrm{pT}$ stage, $\mathrm{pN}$ stage, $\mathrm{pM}$ stage, vascular invasion and lymphatic invasion. 5-year survival rate for the entire cohort was $67.6 \%$ (44-83). Information on post-operative therapy was available for all patients. Patient characteristics are summarized in Table 2. The use of patient data has been approved by the local Ethics Committee of the University of Athens, Greece.

\section{Statistical Analysis}

To determine the most appropriate cut-off score for tumor diameter and to allow optimal classification of patients into pT1-2 and pT3-pT4 as well as pN0 and pN12 stages, Classification and Regression Tree (CART) analysis was performed on the test group of 418 patients. CART generates a clinical decision rule which can be visualized as a "decision-tree". The computer-generated algorithm uses a binary recursive process which splits the data into the best possible combination of variables to optimally classify patients into those with or without the outcome. To measure the classification error as a function of tree size, 10-fold cross-validation experiments were performed. For each of those experiments, data were randomly split into 10 smaller subsets. A backward pruning method was used to choose the best number of nodes from the original tree. Once the 10 trees are built, their classification error rate as a function of tree size is averaged. The tree size that produces the least amount of misclassification is selected as the optimal tree. Simple logistic regression analysis was performed in order to determine the odds of having pT3-4 or pN1-2 with tumors below or above the obtained cut-off score from CART analysis. Odds ratios (OR) and 95\% confidence intervals $(\mathrm{CI})$ were used to determine the effect of tumor diameter on more advanced $\mathrm{pT}$ or $\mathrm{pN}$ classification. Finally, receiver operating characteristic (ROC) curve analysis and the area under the ROC curve (AUC) were used to determine overall accuracy of tumor size on outcome. The closer the AUC value is to 1.0 and the further away from 0.5 , the more tumor size discriminates between $\mathrm{pT}$ and $\mathrm{pN}$ classification. Kaplan-Meier survival curve and the log-rank test were used to evaluate survival time differences in univariate setting. P-values $<0.05$ were considered statistically significant.

\section{Results}

Test Cohort

\section{Tstage}

Of the 482 patients initially included in our study, information on tumor diameter, $\mathrm{pT}$ and $\mathrm{pN}$ stages was avail-
Table 2: Characteristics of rectal cancer patients in the validation cohort $(n=28)$

\begin{tabular}{|c|c|c|}
\hline $\begin{array}{l}\text { Clinco-pathological } \\
\text { features }\end{array}$ & & Frequency N (\%) \\
\hline $\begin{array}{l}\text { Patient age at diagnosis } \\
\text { (years) }\end{array}$ & Median (min-max) & $65(38-82)$ \\
\hline Tumor size (mm) & Median (min-max) & $40(10-70)$ \\
\hline \multirow[t]{2}{*}{ Gender } & Male & $13(46.4)$ \\
\hline & Female & $15(53.6)$ \\
\hline \multirow[t]{2}{*}{ Diagnosis } & Non-mucinous & $26(92.9)$ \\
\hline & Mucinous & $2(7.1)$ \\
\hline \multirow[t]{2}{*}{ pT classification } & pT1-2 & $12(42.9)$ \\
\hline & pT3-4 & $16(57.1)$ \\
\hline \multirow[t]{2}{*}{ pN classification } & pNO & $15(53.6)$ \\
\hline & $\mathrm{pN} 1-2$ & $13(46.4)$ \\
\hline \multirow[t]{2}{*}{ pM classification } & $\mathrm{pMO}$ & $27(96.4)$ \\
\hline & $\mathrm{pM} 1$ & $1(3.6)$ \\
\hline \multirow[t]{2}{*}{ Tumor grade } & G1-2 & $18(78.3)$ \\
\hline & G3 & $5(21.7)$ \\
\hline \multirow{2}{*}{$\begin{array}{l}\text { Vascular or lymphatic } \\
\text { invasion }\end{array}$} & Absent & $25(89.3)$ \\
\hline & Present & $3(10.7)$ \\
\hline \multirow[t]{2}{*}{ Adjuvant therapy } & Absent & $10(35.7)$ \\
\hline & Present & $18(64.3)$ \\
\hline Survival rate (5-years) & $95 \% \mathrm{Cl}$ & $67.6(44-83)$ \\
\hline
\end{tabular}

able in 418 cases. Using CART analysis, a tumor diameter of $34 \mathrm{~mm}$ was found to be most useful for discriminating between patients with early (pT1/pT2) and late (pT3/pT4) $T$ stage. In particular, of the 327 cases with $>34 \mathrm{~mm}$ rectal cancer, $80 \%(\mathrm{n}=261)$ had late $\mathrm{T}$ stage cancers. These patients had a 6.67 (95\%CI: 3.4-12.9) times greater odds of pT3-4 lesions compared to those with $\leq 34 \mathrm{~mm}$ (Table 3). Moreover, $31 / 46$ (67\%) patients with $\leq 29 \mathrm{~mm}$ tumors in diameter were pT1-pT2 (Figure 1). 45 patients had tumors with a diameter of $29-34 \mathrm{~mm}$. Classification of these patients into early or late $\mathrm{T}$ stages was ambiguous 
Table 3: Association of tumor diameter with pT and pN classifications in rectal cancer-test cohort $(n=418)$

\begin{tabular}{|c|c|c|c|c|c|c|}
\hline & & \multicolumn{2}{|c|}{ Frequency $\mathrm{N}(\%)$} & \multirow[t]{2}{*}{ OR (95\%Cl) } & \multirow[t]{2}{*}{ P-value } & \multirow[t]{2}{*}{ AUC } \\
\hline & & $\leq 34 \mathrm{~mm}$ & $>34 \mathrm{~mm}$ & & & \\
\hline \multirow[t]{3}{*}{ pT classification } & pT1-2 & $31(67.4)$ & $88(23.7)$ & $6.67(3.4-12.9)$ & $<0.001$ & 0.66 \\
\hline & pT3-4 & $15(32.6)$ & $284(76.3)$ & & & \\
\hline & & $\leq 29 \mathrm{~mm}$ & $>29 \mathrm{~mm}$ & & & \\
\hline \multirow[t]{2}{*}{ pN classification } & pNO & $35(15.5)$ & $11(5.7)$ & $3.02(1.5-6.1)$ & 0.002 & 0.55 \\
\hline & pN1-2 & $191(84.5)$ & $181(94.3)$ & & & \\
\hline
\end{tabular}

OR: odds ratio. AUC: area under the ROC curve, illustrating discriminatory ability of tumor size for $\mathrm{pT}$ and pN classifications

with $51 \%$ found to be early and $49 \%$ late T stage. Sensitivity and specificity of tumor size for pT3-4 using a cut-off score of $34 \mathrm{~mm}$ were $76.3 \%$ and $67.4 \%$, respectively, with an overall diagnostic accuracy of $66 \%$.

\section{N stage}

A tumor diameter of $29 \mathrm{~mm}$ was most discriminating between node-negative ( $\mathrm{pN} 0)$ and node-positive ( $\mathrm{pN} 1-2)$ patients. Of the 46 patients with $\leq 29$ mm cancers, $76 \%$ (n = 35) had node-negative and $24 \%$ node-positive disease. These patients had an OR of 3.02 (95\%CI: 1.5-6.1) indicating that cases $>29 \mathrm{~mm}$ in diameter had more than a 3fold greater odds of node-positivity compared to cancers that were $\leq 29 \mathrm{~mm}$. Only 7 patients had tumors exceeding $92.5 \mathrm{~mm}$ in size and 6/7 (85.7\%) were node-positive. A large subgroup of patients $(\mathrm{n}=365)$ with tumor diameters from 29 to $92.5 \mathrm{~mm}$ had a similar probability of being classified as either node-negative $(52 \% ; n=190)$ or nodepositive $(48 \%, \mathrm{n}=175)$. Although highly sensitive for pN1-2 stages, tumor size was significantly less specific for pN0 cases (sensitivity and specificity for pN1-2 were $94.3 \%$ and $15.5 \%$, respectively), while the overall diagnostic accuracy was $55 \%$.

\section{Comparison of survival by T stage and tumor size}

The predictive ability of a tumor diameter of $34 \mathrm{~mm}$ for early and late $\mathrm{T}$ stages was validated using survival time. In Figure 2, survival time differences between patients with early and late $\mathrm{pT}$ stages are shown $(\mathrm{p}<0.001)$. Similar differences were observed when compared to survival time differences in patients with $\leq 34$ or $>34 \mathrm{~mm}$ tumor sizes $(\mathrm{p}=0.001)$.

\section{External Validation Cohort}

To validate these findings, a second independent cohort of untreated rectal cancer patients was analyzed. Applying a cut-off of $34 \mathrm{~mm}$ to tumor size and classifying patients in early or late $\mathrm{T}$ stages, the sensitivity, specificity, and overall diagnostic accuracy for late $\mathrm{T}$ stage were $73.7 \%, 77.8 \%$ and $73 \%$, respectively (Table 4 ). For pN classification, using a cut-off of $29 \mathrm{~mm}$, sensitivity, specificity and overall accuracy were $50 \%, 75 \%$ and $56 \%$, respectively. Thus, the high accuracy of tumor size in predicting $\mathrm{T}$ stages and its moderate ability with respect to $\mathrm{N}$ stages were reproduced in this second cohort.

\section{Discussion and conclusions}

The results of this study using test and validation cohorts of more than 400 pre-operatively untreated rectal cancer patients suggest that tumor size at a cut-off of $34 \mathrm{~mm}$ is significantly related to $\mathrm{pT}$ stage. This indicates that tumor size can be used to improve the assessment of pre-operative staging.

Precise pre-operative staging has a crucial role in planning treatment strategy in rectal cancer. Extensive studies have compared the accuracy of different imaging modalities to correctly stage rectal cancers pre-operatively. These studies show that despite considerable improvement in resolution of various imaging techniques, accurate pre-operative staging remains challenging. For example, differentiation between T2 and early T3 stages is often difficult even with MRI due to desmoplastic reaction around the tumor that mimics neoplastic tissue [3134]. Inability to identify lymph nodes containing micrometastases as well as size overlap between reactive nodes and those containing metastases are other major challenges for all imaging modalities including high resolution MRI [33,35-37].

Previous reports have evaluated the association of tumor size, prognosis, cancer recurrence and peri-rectal lymph node involvement. Wolmark and colleagues found that among patients with Dukes C colorectal tumors, 

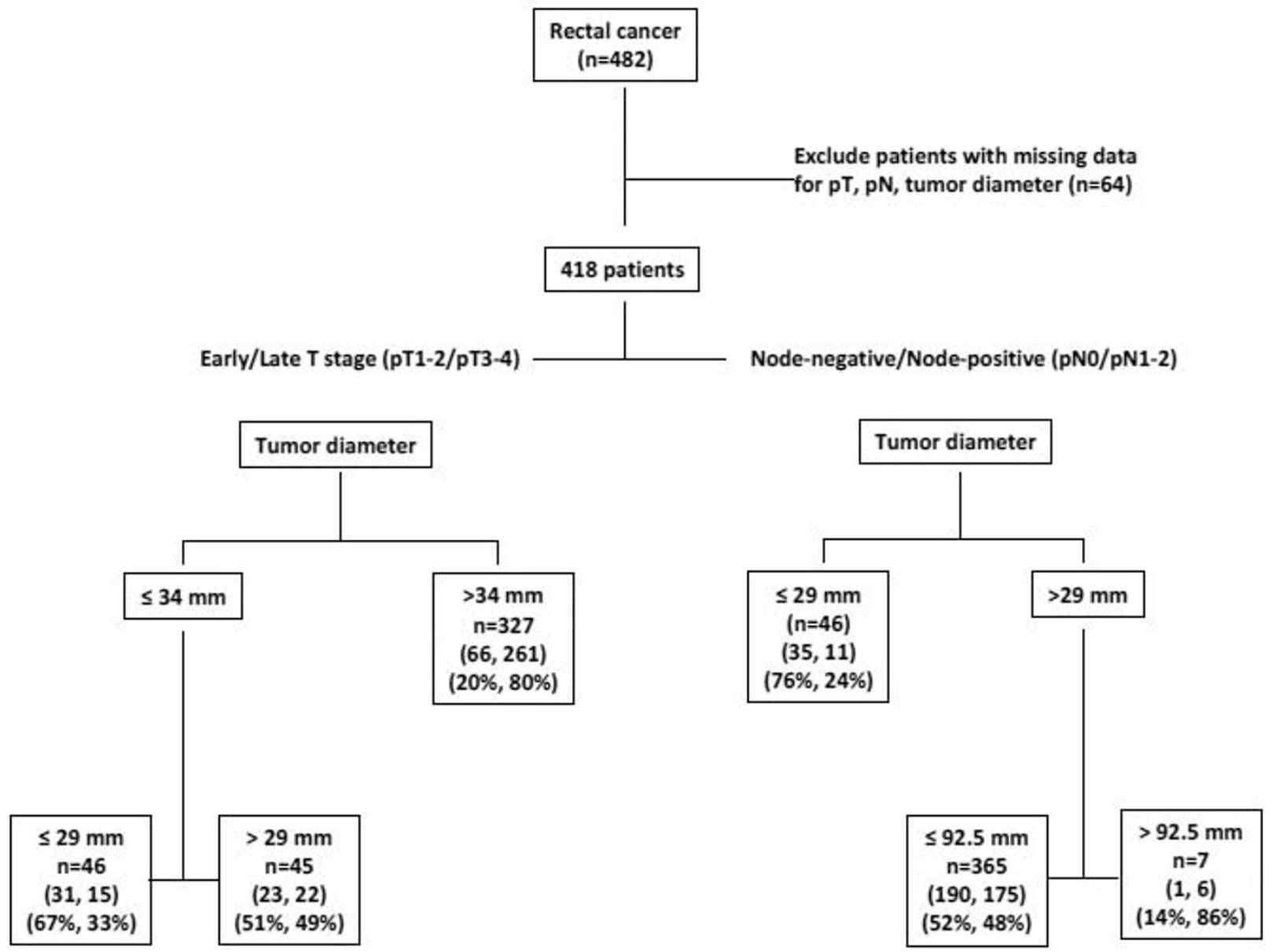

Figure 1 Classification of rectal cancer patients (test cohort) into early and late T stages or into node-negative and node-positive disease based on tumor diameter using classification and regression tree analysis (CART). For the classification of patients by $T$ stage, numbers in parentheses describe (the number of patients with early $T$, late $T$ stage) followed by (percentage of patients with early $T$ and late $T$ stages). For the classification of patients by $\mathrm{N}$ stage, numbers in parentheses describe (the number of patients with node-negative, node-positive disease) followed by (percentage of patients with node-negative, node-positive disease).

depth of penetration was related to tumor size and number of positive lymph nodes [38]. In a comprehensive analysis, Cai and colleagues, reported an independent predictive effect of tumor size along with pre-operative CEA level and tumor differentiation for identifying locally advanced rectal cancer [39]. In a series of 265 pT1 and pT2 colorectal cancer patients including 164 rectal cancers, Chock and Law showed that tumor size was associated with pT stage but not lymph node status [40]. A similar study by Rasheed et al on 303 patients with pT1 and pT2 rectal cancer revealed a direct correlation between tumor size and depth of invasion but not lymph node metastasis [41]. Kikuchi et al reported a direct association between tumor diameter and depth of invasion as well as lack of a correlation between tumor size and lymph node metastasis in 182 colorectal cancer cases [42]. Using $10 \mathrm{~mm}$ as cut off, Matsuda et al showed that depth of invasion but not node involvement was associated with tumor size [43]. Our study suggests for the first time a tumor diameter threshold allowing reproducible prediction of higher T stages (pT3-pT4) and worse survival. The results of this study are in line with most previous reports showing lack of accuracy for tumor size to predict $\mathrm{N}$ stage [44-47]. The study of Zhang et al is among the few reports demonstrating a direct association between tumor size and nodal metastasis [48]. Our study is limited by the fact that it is a retrospective analysis of rectal cancer patients. Additionally, since TME was only introduced in Switzerland for the treatment of rectal cancer in the summer of 1995, nearly all the patients in this study did not undergo this surgical procedure. Thirdly, the assessment of tumor deposits, as required for accurate staging according to the most recent 7th edition of the American Joint Committee on 


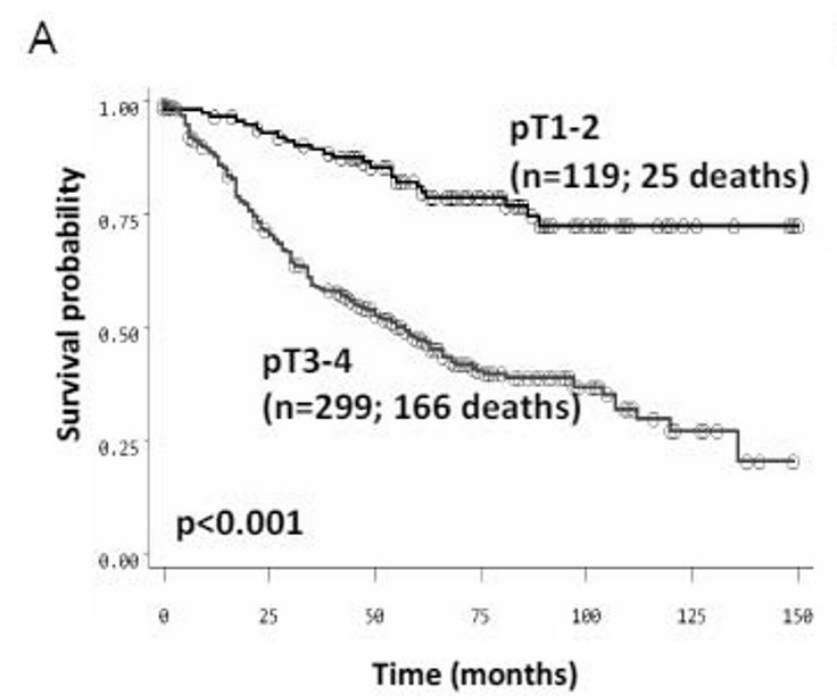

B

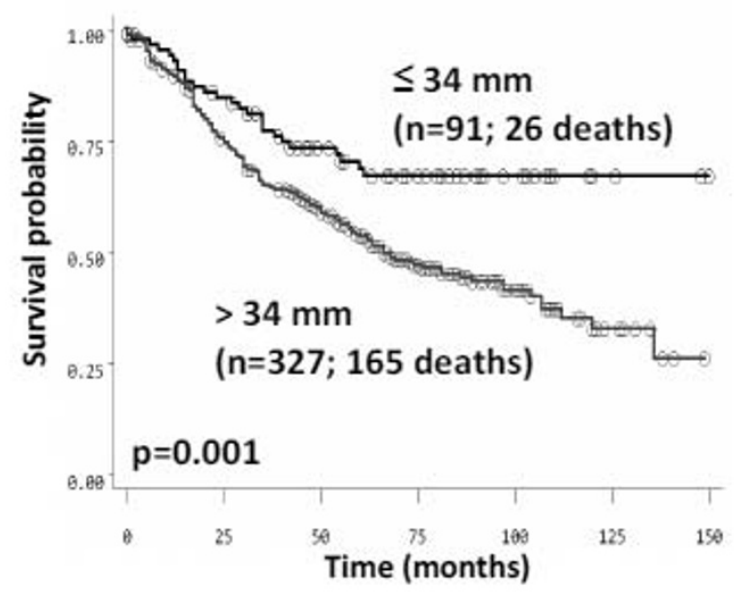

Figure 2 Kaplan-Meier survival curves showing differences in survival time between patients with (A) early (pT1-2) and late (pT3-4) rectal tumors and with (B) $\leq 34 \mathrm{~mm}$ and $>34 \mathrm{~mm}$ rectal tumors.

Table 4: Association of tumor diameter with $\mathrm{pT}$ and $\mathrm{pN}$ classifications in rectal cancer- validation cohort $(\mathrm{n}=\mathbf{2 8})$

\begin{tabular}{|c|c|c|c|c|c|c|}
\hline & & \multicolumn{2}{|c|}{ Frequency N (\%) } & \multirow[t]{2}{*}{ OR (95\%CI) } & \multirow[t]{2}{*}{ P-value } & \multirow[t]{2}{*}{ AUC } \\
\hline & & $\leq 34 \mathrm{~mm}$ & $>34 \mathrm{~mm}$ & & & \\
\hline \multirow[t]{3}{*}{ pT classification } & pT1-2 & $7(77.8)$ & $5(26.3)$ & $9.8(1.5-64)$ & 0.017 & 0.73 \\
\hline & pT3-4 & $2(22.2)$ & $14(73.7)$ & & & \\
\hline & & $\leq 29 \mathrm{~mm}$ & $>29 \mathrm{~mm}$ & & & \\
\hline \multirow[t]{2}{*}{ pN classification } & pNO & $3(75.0)$ & $12(50.0)$ & $3.0(0.3-33.1)$ & 0.37 & 0.56 \\
\hline & $\mathrm{pN} 1-2$ & $1(25.0)$ & $12(50.0)$ & & & \\
\hline
\end{tabular}

OR: odds ratio. AUC: area under the ROC curve, illustrating discriminatory ability of tumor size for $\mathrm{pT}$ and pN classifications

Cancer and International Union against Cancer Classification $(\mathrm{AJCC} / \mathrm{UICC})$ were not evaluated in this series; staging was performed according to the 6th edition of the cancer staging manual. However, since this study was not focused on prognosis of patients with rectal cancer but rather on the predictive ability of tumor size on $\mathrm{pT}$ and $\mathrm{pN}$ stage, the lack of information of these and other prognostic factors only minimally affects the major results of this study. In addition, this analysis benefits from a large number of rectal cancer patients as well as the use of a test and validation group. The results of the latter confirmed that the determined cut-off score of $34 \mathrm{~mm}$ leads to similar prediction of advanced $\mathrm{pT}$ stage.

In conclusion, tumor size may help to determine the best treatment option for rectal cancer patients. A tumor size of $>34 \mathrm{~mm}$ is highly related to more advanced $\mathrm{pT}$ stages.

Competing interests

The authors declare that they have no competing interests.
Authors' contributions

IZ, PM and AL contributed to conception and design, manuscript drafting, analysis and data interpretation; EK and FL made critical revisions for intellectual content and data interpretation while EP and GP contributed to data acquisition. All authors gave their approval of the final manuscript.

\section{Author Details}

${ }^{1}$ Institute of Pathology, University Hospital of Basel, Basel, Switzerland, 2Department of Pathology, University of California San Diego, San Diego, CA, USA, ${ }^{3}$ Second Department of Pathology, University of Athens, Athens, Greece, 4Fourth Department of Surgery, University of Athens, Athens, Greece, 5First

Department of Pathology, University of Athens, Athens, Greece and ${ }^{6}$ Department of Gastroenterology, University Hospital of Basel, Basel, Switzerland

Received: 9 December 2009 Accepted: 15 June 2010 Published: 15 June 2010

\section{References}

1. Daniels IR, Fisher SE, Heald RJ, Moran BJ: Accurate staging, selective preoperative therapy and optimal surgery improves outcome in rectal cancer: a review of the recent evidence. Colorectal Dis 2007, 9(4):290-301.

2. O'Neil BH, Tepper JE: Current options for the management of rectal cancer. Curr Treat Options Oncol 2007, 8(5):331-338. 
3. Glimelius B, Oliveira J: Rectal cancer: ESMO clinical recommendations for diagnosis, treatment and follow-up. Ann Oncol 2008, 19(Suppl 2):ii31-32

4. Wong RK, Tandan V, De Silva S, Figueredo A: Pre-operative radiotherapy and curative surgery for the management of localized rectal carcinoma. Cochrane Database Syst Rev 2007, 2:CD002102.

5. Akasu T, linuma G, Takawa M, Yamamoto S, Muramatsu Y, Moriyama N: Accuracy of high-resolution magnetic resonance imaging in preoperative staging of rectal cancer. Ann Surg Oncol 2009, 16(10):2787-2794

6. Badger SA, Devlin PB, Neilly PJ, Gilliland R: Preoperative staging of rectal carcinoma by endorectal ultrasound: is there a learning curve? Int Colorectal Dis 2007, 22(10):1261-1268.

7. Beer-Gabel M, Assouline Y, Zmora O, Venturero M, Bar-Meir S, Avidan B: A new rectal ultrasonographic method for the staging of rectal cancer. Dis Colon Rectum 2009, 52(8):1475-1480.

8. Brown G, Davies S, Williams GT, Bourne MW, Newcombe RG, Radcliffe AG, Blethyn J, Dallimore NS, Rees BI, Phillips CJ, Maughan TS: Effectiveness of preoperative staging in rectal cancer: digital rectal examination, endoluminal ultrasound or magnetic resonance imaging? $\mathrm{Br} J$ Cancer 2004, 91(1):23-29

9. Landmann RG, Wong WD, Hoepfl J, Shia J, Guillem JG, Temple LK, Paty PB, Weiser MR: Limitations of early rectal cancer nodal staging may explain failure after local excision. Dis Colon Rectum 2007, 50(10):1520-1525.

10. Mathur P, Smith JJ, Ramsey C, Owen M, Thorpe A, Karim S, Burke C, Ramesh S, Dawson PM: Comparison of CT and MRI in the pre-operative staging of rectal adenocarcinoma and prediction of circumferential resection margin involvement by MRI. Colorectal Dis 2003, 5(5):396-401.

11. Bartram C, Brown G: Endorectal ultrasound and magnetic resonance imaging in rectal cancer staging. Gastroentero/ Clin North Am 2002, 31(3):827-839.

12. Pijl ME, Chaoui AS, Wahl RL, van Oostayen JA: Radiology of colorectal cancer. Eur J Cancer 2002, 38(7):887-898.

13. Zorcolo L, Fantola G, Cabras F, Marongiu L, D'Alia G, Casula G: Preoperative staging of patients with rectal tumors suitable for transanal endoscopic microsurgery (TEM): comparison of endorectal ultrasound and histopathologic findings. Surg Endosc 2009 23(6):1384-1389.

14. Beets-Tan RG, Beets GL, Vliegen RF, Kessels AG, Van Boven H, De Bruine A, von Meyenfeldt MF, Baeten CG, van Engelshoven JM: Accuracy of magnetic resonance imaging in prediction of tumour-free resection margin in rectal cancer surgery. Lancet 2001, 357(9255):497-504.

15. Blomqvist $L, H o l m T$, Rubio C, Hindmarsh $T$ : Rectal tumours--MR imaging with endorectal and/or phased-array coils, and histopathological staging on giant sections. A comparative study. Acta Radiol 1997 38(3):437-444.

16. Blomqvist L, Machado M, Rubio C, Gabrielsson N, Granqvist S, Goldman S, Holm T: Rectal tumour staging: MR imaging using pelvic phased-array and endorectal coils vs endoscopic ultrasonography. Eur Radiol 2000, 10(4):653-660

17. Brown G, Richards CJ, Newcombe RG, Dallimore NS, Radcliffe AG, Carey DP, Bourne MW, Williams GT: Rectal carcinoma: thin-section MR imaging for staging in 28 patients. Radiology 1999, 211(1):215-222

18. Jao SY, Yang BY, Weng HH, Yeh CH, Lee LW: Evaluation of gadoliniumenhanced T1-weighted MRI in the preoperative assessment of local staging in rectal cancer. Colorectal Dis 2009 in press.

19. Jhaveri KS, Sadaf A: Role of MRI for staging of rectal cancer. Expert Rev Anticancer Ther 2009, 9(4):469-481.

20. Kuremsky JG, Tepper JE, MCLeod HL: Biomarkers for response to neoadjuvant chemoradiation for rectal cancer. Int J Radiat Oncol Biol Phys 2009, 74(3):673-688.

21. Kikuchi M, Mikami T, Sato T, Tokuyama W, Araki K, Watanabe M, Saigenji K, Okayasu I: High Ki67, Bax, and thymidylate synthase expression well correlates with response to chemoradiation therapy in locally advanced rectal cancers: proposal of a logistic model for prediction. $\mathrm{Br}$ J Cancer 2009, 101(1):116-123.

22. Negri FV, Campanini N, Camisa R, Pucci F, Bui S, Ceccon G, Martinelli R, Fumagalli M, Losardo PL, Crafa P, Bordi C, Cascinu S, Ardizzoni A: Biological predictive factors in rectal cancer treated with preoperative radiotherapy or radiochemotherapy. Br J Cancer 2008, 98(1):143-147.

23. Zlobec I, Vuong T, Compton CC, Lugli A, Michel RP, Hayashi S, Jass JR: Combined analysis of VEGF and EGFR predicts complete tumour response in rectal cancer treated with preoperative radiotherapy. $\mathrm{Br}$ J Cancer 2008, 98(2):450-456

24. Singletary SE, Connolly JL: Breast cancer staging: working with the sixth edition of the AJCC Cancer Staging Manual. CA Cancer J Clin 2006 56(1):37-47. quiz 50-31

25. Adachi Y, Oshiro T, Mori M, Maehara Y, Sugimachi K: Tumor size as a simple prognostic indicator for gastric carcinoma. Ann Surg Onco/ 1997, 4(2):137-140.

26. Li C, Oh SJ, Kim S, Hyung WJ, Yan M, Zhu ZG, Noh SH: Risk factors of survival and surgical treatment for advanced gastric cancer with large tumor size. J Gastrointest Surg 2009, 13(5):881-885.

27. Liu X, Xu Y, Long Z, Zhu H, Wang Y: Prognostic significance of tumor size in T3 gastric cancer. Ann Surg Oncol 2009, 16(7):1875-1882.

28. Saito H, Osaki T, Murakami D, Sakamoto T, Kanaji S, Oro S, Tatebe S, Tsujitani S, Ikeguchi M: Macroscopic tumor size as a simple prognostic indicator in patients with gastric cancer. Am J Surg 2006, 192(3):296-300

29. Wang X, Wan F, Pan J, Yu GZ, Chen Y, Wang JJ: Tumor size: a nonneglectable independent prognostic factor for gastric cancer. J Surg Oncol 2008, 97(3):236-240

30. Lugli A, Zlobec I, Singer G, Kopp Lugli A, Terracciano LM, Genta RM: Napoleon Bonaparte's gastric cancer: a clinicopathologic approach to staging, pathogenesis, and etiology. Nat Clin Pract Gastroenterol Hepatol 2007, 4(1):52-57.

31. Engelen SM, Beets GL, Beets-Tan RG: Role of preoperative local and distant staging in rectal cancer. Onkologie 2007, 30(3):141-145.

32. Karantanas $\mathrm{AH}$, Yarmenitis S, Papanikolaou N, Gourtsoyiannis N: Preoperative imaging staging of rectal cancer. Dig Dis 2007 25(1):20-32

33. Klessen C, Rogalla P, Taupitz M: Local staging of rectal cancer: the current role of MRI. Eur Radiol 2007, 17(2):379-389.

34. Rao SX, Zeng MS, Xu JM, Qin XY, Chen CZ, Li RC, Hou YY: Assessment of T staging and mesorectal fascia status using high-resolution MRI in rectal cancer with rectal distention. World J Gastroenterol 2007 13(30):4141-4146.

35. Lahaye MJ, Beets GL, Engelen SM, Kessels AG, de Bruine AP, Kwee HW, van Engelshoven JM, van de Velde CJ, Beets-Tan RG: Locally advanced rectal cancer: MR imaging for restaging after neoadjuvant radiation therapy with concomitant chemotherapy. Part II. What are the criteria to predict involved lymph nodes? Radiology 2009, 252(1):81-91.

36. Muthusamy VR, Chang KJ: Optimal methods for staging rectal cancer. Clin Cancer Res 2007, 13(22 Pt 2):6877s-6884s.

37. Smith N, Brown G: Preoperative staging of rectal cancer. Acta Oncol 2008, 47(1):20-31.

38. Wolmark N, Fisher ER, Wieand HS, Fisher B: The relationship of depth of penetration and tumor size to the number of positive nodes in Dukes $C$ colorectal cancer. Cancer 1984, 53(12):2707-2712

39. Cai G, Xu Y, Zhu X, Peng J, Li Z, Xiao C, Du X, Zhu J, Lian P, Sheng W, Guan $Z$, Cai S: A simple scoring system based on clinical features to predict locally advanced rectal cancers. J Gastrointest Surg 2009, 13(7):1299-1305.

40. Chok KS, Law WL: Prognostic factors affecting survival and recurrence of patients with pT1 and pT2 colorectal cancer. World J Surg 2007 31(7):1485-1490.

41. Rasheed S, Bowley DM, Aziz O, Tekkis PP, Sadat AE, Guenther T, Boello ML, McDonald PJ, Talbot IC, Northover JM: Can depth of tumour invasion predict lymph node positivity in patients undergoing resection for early rectal cancer? A comparative study between T1 and T2 cancers. Colorectal Dis 2008, 10(3):231-238.

42. Kikuchi R, Takano M, Takagi K, Fujimoto N, Nozaki R, Fujiyoshi T, Uchida Y: Management of early invasive colorectal cancer. Risk of recurrence and clinical guidelines. Dis Colon Rectum 1995, 38(12):1286-1295.

43. Matsuda T, Saito Y, Fujii T, Uraoka T, Nakajima T, Kobayashi N, Emura F, Ono A, Shimoda T, Ikematsu H, Fu Kl, Sano Y, Fujimori T: Size does not determine the grade of malignancy of early invasive colorectal cancer. World J Gastroentero/ 2009, 15(22):2708-2713.

44. Brodsky JT, Richard GK, Cohen AM, Minsky BD: Variables correlated with the risk of lymph node metastasis in early rectal cancer. Cancer 1992, 69(2):322-326

45. Choi PW, Yu CS, Jang SJ, Jung SH, Kim HC, Kim JC: Risk factors for lymph node metastasis in submucosal invasive colorectal cancer. World J Surg 2008, 32(9):2089-2094. 
46. Nascimbeni R, Burgart LJ, Nivatvongs S, Larson DR: Risk of lymph node metastasis in T1 carcinoma of the colon and rectum. Dis Colon Rectum 2002, 45(2):200-206

47. Saclarides TJ, Bhattacharyya AK, Britton-Kuzel C, Szeluga D, Economou SG: Predicting lymph node metastases in rectal cancer. Dis Colon Rectum 1994, 37(1):52-57.

48. Zhang H, Chen CS, Cong JC, Qiao L, Hasegawa T, Takashima S:

Clinicopathological characteristics of advanced colorectal cancer 30 mm or smaller in diameter. Chin Med Sci J 2007, 22(2):98-103.

\section{Pre-publication history}

The pre-publication history for this paper can be accessed here: http://www.biomedcentral.com/1471-230X/10/61/prepub

doi: $10.1186 / 1471-230 X-10-61$

Cite this article as: $Z$ lobec et al., Role of tumor size in the pre-operative management of rectal cancer patients BMC Gastroenterology 2010, 10:61

Submit your next manuscript to BioMed Central and take full advantage of:

- Convenient online submission

- Thorough peer review

- No space constraints or color figure charges

- Immediate publication on acceptance

- Inclusion in PubMed, CAS, Scopus and Google Scholar

- Research which is freely available for redistribution

Submit your manuscript at www.biomedcentral.com/submit
C) Biomed Central 